\title{
Multiparous women's confidence to have a publicly-funded homebirth: a qualitative
} study

\section{ABSTRACT}

Background: Hospital birth is commonly thought to be a safer option than homebirth, despite many studies showing similar rates of safety for low risk mothers and babies when cared for by qualified midwives with systems of back-up in place. Recently in Australia, demand has led to the introduction of a small number of publicly-funded homebirth programs. These offer homebirth to selected women who previously would not have considered this option. Women's confidence in having a homebirth through a publicly-funded homebirth program in Australia has not yet been explored.

Aim: The aim of the study was to explore the reasons why multiparous women feel confident to have a homebirth within a publicly-funded model of care in Australia.

Methods: Ten multiparous English-speaking women who chose to have a homebirth with the St George Hospital Homebirth Program were interviewed in the postnatal period using semi-structured, open-ended questions. Interviews were transcribed, then a thematic analysis was undertaken. Data were part of a wider set collected as part of a doctoral study. Results: Women, having already experienced a normal birth, demonstrated a strong confidence in their ability to give birth at home and described a confidence in their bodies, their midwives, and the health system. Women weighed up the risks of homebirth through information they gathered and integration with their previous experience of birth, their family support and self-confidence.

Discussion: Women choosing publicly-funded homebirth display strong confidence in both themselves to give birth at home, and their belief in the health system's ability to cope with any complications that may arise. 
Implications for practice: Many women may benefit from access to publicly-funded homebirth models of care. This should be explored.

Key words: childbirth, homebirth, risk, confidence

\section{1 words}

\section{INTRODUCTION}

Homebirth is not a common choice amongst women in many parts of the western world [13]. In Australia, around $0.3 \%$ of women [1], and in the UK $2.7 \%$ of women give birth at home [3], although this is increasing [4]. The rate in the United States of America is $0.6 \%$ [2]. The exception to most developed countries is the Netherlands, where the rate is around $30 \%$ [5].

In Australia, women wanting a homebirth have historically employed private practising midwives to provide care, although in recent years this has become increasingly difficult [8]. Many professional groups in Australia, including the Australian Medical Association (AMA) and the Royal Australian and New Zealand College of Obstetricians and Gynaecologists (RANZCOG), do not support homebirth [6, 7]. However, a small number of women continue to choose home as their preferred place of birth. A small number of publicly-funded homebirth services have been established in a number of Australian states and territories to accommodate women's requests. These includes models in the Hunter New England area, the South Eastern Sydney and Illawarra Health Service (NSW), [9] South Australia [10], Northern Territory and Western Australia [11] and recently in Victoria [12].

Most women have some degree of difficulty arranging a homebirth (REF Shaw 2005). Women who do have a local service often have to carefully negotiate their wishes to their partners and family, become particularly strategic about who they talk to, and encounter 
negativity around their choice of birth place $[13,14]$. Women's confidence to process the decision to have a homebirth, and gain the family support, should not be underestimated. Confidence is 'a feeling of self-assurance arising from one's own abilities or qualities' [15]. This is similar to the concept of self-efficacy, which is the ability to believe in one's own capabilities, and has been measured in quantitative studies [16-18]. Understanding how women develop the confidence to have a homebirth in a publicly-funded model was the impetus for this study.

Many studies describe women's reasons for choosing homebirth $[19,20]$, and the safety and risk aspects [20-24]. Previous work has linked homebirth decisions to notions of confidence. For example, Dahlen et al. [25] found women choosing homebirth were more willing to take responsibility for their pregnancy, labour and birth, whereas women giving birth in hospital were more likely to give this over to health professionals. In Sweden, Lindgren [26] describes, in a small qualitative study of women's perception of risks and homebirth, that women have confidence in themselves to give birth, and believe in the capabilities of their midwives. A larger study from Canada had similar findings; with strong themes relating to the support and confidence instilled in women by the midwives [27]. Our study built on these findings in the context of a publicly-funded model known as the St George Hospital Homebirth Program in Sydney, Australia.

Confidence in childbirth is influenced by individual beliefs. Childbirth can be seen predominantly in two ways, through a 'biomedical' (or 'technocratic') model or 'social' model, depending on personal philosophy $[28,29]$. The biomedical model emphasises the elements of danger in pregnancy and birth, whereas the social model philosophy views birth as a more natural physiological event. Similar attitudes to the risks of childbirth are held by both health professionals and women, and as such, can influence decision-making based on quite different perceptions of risk. Women choosing homebirth often veer towards the 'social' 
model of birth and believe risks involved in childbirth are not limited to the home, and are part of a more complicated phenomenon [26].

Dahlen [25] describes the different weights placed on risk in childbirth by different health professionals. For example, obstetricians, and those more aligned with the biomedical model of birth will describe a risk as being likely to happen 1:1000, whereas midwives, and those with the 'social' philosophy, describe the same risk as not happening 999 times out of a thousand [25]. This subtle difference in delivering information can contribute to women's positive attitudes and confidence in their ability to give birth at home. A similar difference in birth philosophy and risk has been found by Cheyney and Everson [30] where less collaboration between hospital staff and homebirth practitioners resulted in hospital staff believing that homebirth was far more dangerous than studies indicate. Homebirth midwives believed that hospital staff had a skewed view of homebirth, as they only saw the women who needed transfer. Similarly, the wider community may also have this distorted view of homebirth, often fuelled by the media [31,32].

\section{The studied Homebirth Program}

The studied Homebirth Program began operation in 2005 and was the first to operate a publicly-funded homebirth model in NSW. To date 103 women have had a homebirth through the service [33]. The Program is located in the southern suburbs of Sydney (NSW) and operates through a hospital-based Birth Centre [33]. Eight midwives work within the Birth Centre, four of whom can be the primary midwife for women who choose homebirth. Primary midwives have attended at least five births at home, have undertaken the Advanced Life Support in Obstetrics (ALSO) course, a rigorous credentialing process [34], practice review and completed competencies in resuscitative skills, cannulation and perineal suturing. All women at low risk of obstetric complications who book into the Birth Centre are given the choice of having a homebirth. Women who plan to have a vaginal birth after caesarean in the Birth Centre, or who develop risk factors during pregnancy are not given 
the option.

The aim of this study was to explore the confidence of multiparous women who choose a homebirth within the St George Hospital Homebirth Program, Sydney, as part of a larger study of the influences on women choosing homebirth. The research question was to investigate why women have the confidence to choose a publicly-funded homebirth.

\section{METHODS}

\section{Design}

A qualitative study of multiparous women who were booked to have a homebirth with the St George Hospital Homebirth Program was undertaken. Approval to conduct the study was obtained by the Human Research Ethics Committee at South Eastern Sydney Illawarra Health Service and the University of Technology, Sydney.

\section{Sample}

Ten multiparous English-speaking women who chose to have a homebirth within the St George Hospital Homebirth Program were interviewed between September 2009 and January 2010. Women were asked to participate in the study if they had booked a homebirth during their pregnancies. Potential participants were approached by the midwives employed in the Birth Centre during an antenatal visit The first ten women approached agreed to participate. Women who were transferred to hospital care during their pregnancy or labour were also included. Multiparous women were selected as this was a relatively homogenous sample of women, and the majority of women who book on the homebirth program have experienced a previous vaginal birth. A sample of ten was seen as an adequate number to explore the concept of confidence in women choosing a homebirth.

\section{Data collection}

Women were interviewed for approximately one hour in their homes between six weeks and six months postpartum. A semi-structured, open-ended question technique was used. 
Questions such as 'why did you choose a homebirth?' and 'what helped you decide to have a homebirth?' were asked. Interviews were audio-taped and transcribed by the author, and participants were de-identified during the transcription phase. Demographic data were collected at the interviews, including age, parity, marital status, educational level and country of birth.

\section{Data analysis}

An analysis of the ten transcriptions was undertaken using thematic analysis. Thematic analysis is an ideal way of analysing interview data when participants are describing experiences as it focuses on identifiable themes and patterns of living and/or behaviour [35]. Through this method, stories are structured to form a comprehensive picture of a collective experience. A constant comparative method of analysis was used whereby the data were compared for similarities and differences, then coded, compared and clustered, and categories formed. Audit trails were kept detailing the raw data and corresponding categories. As more data were collected, these categories moved and changed related to the data content. Management of the data was assisted by using NVivo software [36].

\section{FINDINGS}

The participants were multiparous, between 21 and 39 years old, and all except one had completed further educational qualifications after completing high school. Four women had tertiary qualifications. All were married or in stable relationships with their partners, spoke English as their first language and were born in Australia, except one woman who was born in Malaysia. None of the women had had a previous birth at home. Five women had one previous normal birth, three women had two, and two had three. Seven of the ten women had a homebirth, and three were transferred intrapartum (one for labour dystocia, one for prolonged rupture of membranes, and one for reasons surrounding childcare arrangements). All women, including those who were transferred to hospital, stated they would choose a 
homebirth for their next birth, suggesting that the responses of the transferred women were not more negative however our study did not investigate this particular issue.

There were different views and experiences expressed in the study, however dominant themes of confidence were present in all women interviewed. The themes from the data were 'confidence in my own body', 'having confidence in the midwives', 'having confidence in the health system', and 'processing confidence and risk'. In relation to these themes, data saturation was reached within the sample after the ten interviews.

\section{Confidence in my own body}

In this theme, women expressed their independence, including concepts such as being different, being decision-makers, being assertive, and being physically and mentally well. All of these concepts culminated in women feeling confident and being able to choose a homebirth; they felt equipped to be responsible for themselves during their labour and birth, and although aware of the necessity for support, expressed their confidence to retain control by choosing a homebirth. This was often described as an aspect of themselves that grew from other personal life experiences. For example, one woman described her chronic respiratory disease as a teenager and the alternative treatment methods she used. This influenced her ability to investigate and embrace homebirth when she became pregnant.

Women described how they had confidence in their bodies; and an innate confidence in their ability to give birth. They identified with being physically and mentally well, with a desire to be in control. One woman expressed:

"With this baby [homebirth] I really wanted to be in control and I knew that my body was capable and I didn't have any issues." 
Women and their partners were reassured by having had a previous normal birth. The experience of their previous birth was usually positive, and the knowledge that their bodies had undergone and coped with the birth process provided reassurance that their bodies would act similarly. A number of women wanted to avoid medication during their labour. One woman described her confidence to labour without medication:

"I had done it before - twice without any medication - I didn't have any pain relief so I knew that I could do it without that"

\section{Having confidence in the midwives}

Women had confidence in the midwives who cared for them especially their skills, knowledge, and attention to detail. The midwives were very influential to women's choice as they shared information and allayed fears. The ability of the midwives to address all of their questions with ease; their personable manner, and the respect given to women seems to have been responsible for the close trusting relationship that developed during pregnancy. The positive approach to birth expressed by the midwives was important, and the subtle way they facilitated women's decisions regarding place of birth was appreciated. For example, women were given the choice to change to hospital care at any time during their pregnancy and labour. This approach meant women and their partners trusted the midwives to provide appropriate skilled care, and advocate for them, if necessary. For example, one woman said:

"... I was very well watched, and even when I was having her, like in full labour, ready to pull the plug 'couldn't do it anymore!' going through my transition stage, the [midwives] were watching me and timing everything and checking me probably more than they would if I was in the hospital, just to make sure that there wasn't any problems, and I felt very confident and very comfortable with that. I think that if there was any 'oh you'll be all right, l'll come back and check you in ten minutes' then I 
probably wouldn't have coped but I knew they were controlling the situation in a very passive way"

Women who attended antenatal classes (five of the ten women) expressed the value of the information they received. The knowledge they gained solidified their confidence to pursue a homebirth, especially for those who attended classes that focused on natural birth. One woman explained how attending antenatal classes affected her:

'he [antenatal educator] did leave me feeling very confident you know that a woman's body is made to do it, and all you have to do is do it!'

\section{Having confidence in the health system as backup}

Despite women choosing to give birth outside of the hospital, they still displayed confidence in the health system. Many women expressed their feelings of safety by having the back-up of the hospital and ambulance service, and the choice to easily transfer to hospital care if necessary. A number of women felt they were so low-risk that the potential problems of being in the hospital (or even just travelling to the hospital) outweighed those of staying at home. A minority of women expressed their desire to avoid intervention, and didn't trust the hospital-based staff to facilitate their wishes in this respect. Others expressed that they wished to avoid the 'temptation' of drugs and intervention, knowing they could do without it, but mindful that they were vulnerable to agree to medication at the height of their labour. One woman described her feelings of security by being cared for by a hospital-based program:

'I just like the idea of the backup there, the continuity.. I just like the fact that I go to the hospital for my appointments and the hospital is the one looking after me.' 
Another woman's family were similarly reassured:

'Some of my family thought it was really nice and really good that I was already a patient there and transfer would be really smooth. If I had to transfer it would be OK'

The flexibility of the publicly-funded homebirth program was appreciated. Women did not need to make a firm decision about having a homebirth; they were given time to decide. One woman expressed how this worked for her:

'So once I got past the anxiety issues, and making that final decision, and knowing that if I didn't want to go ahead with it then I could always back out and still go to the hospital ..I was fine, I was very relaxed about it.. just wanted to leave the window open, because I liked the idea of doing it but I wasn't completely ready to make that decision, and I think as I got further along in my pregnancy, it was easier for me to make that decision'

\section{Weighing up the risks and benefits}

Women weighed up the risks of homebirth and this knowledge increased their confidence in their choice. There were similarities amongst the women with how they processed the concept of risk, and often they would use words such as 'safety', instead of 'risk'. Most women spent time talking to others who had either had a homebirth, or who knew women who had given birth at home. Central to this were the midwives who worked within the homebirth program. One woman expressed this as:

just that it was a big thing for me, with my anxieties and things, knowing that the procedures, that the [midwives] at St George got grilled - I needed to know absolutely everything about how it worked' 
Women gathered information about homebirth from books, the internet (blogs, chat rooms), other health professionals and friends. This, together with their previous experience of birth and the family, culminated in confidence that grew in strength during their pregnancy. Often women only felt ready to confirm their choice of birth place later in their pregnancy after this process had taken place. One woman said:

'I knew that if I was well monitored in my pregnancy, then I could have one, and that's what led me to that level of wanting to have a homebirth. I didn't actually decide to have a homebirth until I had had my 28-week gestational diabetes test, because I had had a false positive with that, so then after I'd had my second test for that then I decided that yes, I wanted to go ahead and have a homebirth. I needed to have everything clear in my head that everything was going to be healthy for me to be able to have a homebirth'

Most women based the expectations of their homebirth on their previous birth experience, and the level of medical intervention they needed at that time. This gave them a point of reference regarding the risk of complications during their planned homebirth, and was an important element to their confidence in planning a homebirth.

'I think if I'd had a very challenging, a difficult labour, then perhaps I would think I needed the medical support, you know what I mean, if something had gone wrong the first time, maybe I would have been thinking I need to be close, I need the medical support, and all that'

Some women wanted their birth to be a family event, which was something they felt they could not get in hospital. They wanted their children involved, and did not want their husbands to leave at the end of hospital visiting time. One woman said: 
'I wanted him [previous child] involved, I wanted him there and I wanted it to be a family thing, a family affair and I knew it was, l'd done a lot of research and reading about it and I knew it was a safe option'

Women went to great lengths to avoid talking to people, including health professionals, who would be negative of homebirth. They also wished to avoid confrontation, and even as their confidence to birth at home grew, they tired of explaining and justifying their choice. Women did not necessarily avoid talking about the possibility of adverse events at home, they merely wished to talk with people who were knowledgeable and encouraging, rather than alarmist and negative. One woman, who worked within the hospital system, describes her feelings after talking with her general practitioner:

$\therefore$..because there definitely was a bit of negative energy there, because as you know they just come from that risk perspective, and its all about risk management and "these horrible things go wrong"'

Women placed an emphasis on their social situation when processing risk. Their family's involvement with the birth, a strong wish to avoid travelling to the hospital in labour, and an overwhelming desire for a calm relaxing environment were all important. These factors were given prime importance in women who choose homebirth, and the risks of birth complications were thought of as negligible, mostly due to their confidence of having experienced a previous normal birth. One woman described the hospital as being superfluous to her needs for her second baby:

'Having done it the first time [hospital birth] I felt I didn't need any of that the second time.. so taking that out of it, what did the hospital provide that really - I didn't need anything that the hospital provided so I didn't really see the need to go to hospital' 
It is acknowledged that the experience of publicly-funded homebirth may have influenced the responses of women regarding their confidence in choosing this model of care. However, women in the study who were transferred intrapartum remained positive of their choice to have a homebirth. This may show that publicly-funded homebirth is beneficial for increasing women's confidence regardless of the eventual outcome, although this needs further exploration. One woman expressed this after being transferred to hospital for labour dystocia:

'I still strongly think that home is the place to be.. yes I still will definitely plan another homebirth'

\section{Discussion}

This study found that multiparous women who had experienced at least one previous normal birth felt confident to give birth at home. The reasons for this confidence were the back-up of the hospital, a strong trust in the abilities of the midwives, and their own personal strength to achieve a homebirth. They weighed up the risks of home and hospital birth, and felt they were not at an increased risk of birth complications by having their babies at home.

Much of the related literature supports the findings of this study. Lindren et al. [26] also found that women were confident in their ability to achieve homebirth [26]. Other literature described how women did not dwell on the possibility of negative outcomes or complications, but surrounded themselves with like-minded people who supported their decision [37, 38]. Similarly, women sought antenatal courses that promoted and built on their confidence to have a normal birth.a [39][40]ADD GIBBINS 2001 REF. The multiparous sample in our study also held an advantage, having had a prior normal birth, whereas primiparous women have been reported to have higher levels of birth-related fear [41] which has been linked to labour dystocia and emergency caesarean section [42]. Hence much of 
the confidence described in our study appeared to be grounded in past experience, and is key to choosing a homebirth.

As part of building their confidence to choose a homebirth, women in this study weighed up the risks and benefits. Decision-making and risk assessment are complex issues used within the healthcare environment. Modern society has seen a growth of a 'risk culture' in health care as a result of litigation and high societal expectations of health care in general. Notions of risk can affect the building of confidence. Decision-making and risk perception have a close relationship [43], and trust in caregivers greatly influences women's decision-making $[44,45]$. Pilley Edwards and Murphy-Lawless [46] discuss the rise of technology and the greatly expanded perception of risk around new science and treatments in maternity care. They conclude this has led to the labelling of women who contest the medical definitions of risk as 'immoral', despite the risk factors in question really being little more than 'probabilistic logic' (p. 38). Women choosing homebirth will often come up against the more conventional views of risk and safety, and have to defend their decisions. Women in our study avoided talking with people who they felt would be negative.

Women in this study believed the risks of serious problems occurring were small, and through surrounding themselves with like-minded people, the positive and normal features of birth were emphasised and built on through pregnancy. In this way, women displayed selfprotective confidence, either avoiding potential conflict, or tired of the repetition involved in having to constantly explain their choice. This was also found by Dahlen et al., [45] and Lindgren [38] who reported that women avoided talking to people about childbirth-related risks, and occasionally resorted to lying to avoid conversations with particular health professionals.

The interpretation of risk can also differ between women. For example, some women believe the risks involved in having a hospital birth outweigh those of having a homebirth [44], 
although the majority believe hospital birth to be safer [47]. This was apparent in the women in our study; they were confident that their risks of complications were equal, or lower, by having their babies at home. The women were certain their total birth experience would be better at home, and this holistic view emphasised the social aspects of birth while minimising the risk of complications in labour and birth.

Differences of perceived risk are discussed by Williams [43], who feels the concept of risk focuses on the physical and neglects important issues such as financial, psychological and social impacts; there are many complex factors at play when presented with risk information - which is apparent when women choose a homebirth. Bailes and Jackson [48], in a case study, describe the non-hierarchical collaborative approach between women, midwives and the medical system in a homebirth scenario. The collaborative approach between the medical, ambulance and midwifery staff at St George Hospital may be a factor that serves to strengthen the confidence and trust women have in their caregivers, and facilitates women's overall confidence in their decision to give birth at home.

The flexibility of the publicly-funded homebirth program gave women control over their birthplace and built confidence. Women booked to have a homebirth could, at any time, choose to give birth in the Birth Centre instead. This ensured women felt safe and comfortable in their birthplace, and back-up care in the hospital was always available. The importance of women feeling in control during labour and birth has been documented extensively and is closely linked to women's satisfaction [19, 49, 50]. Similarly, women's feelings of safety has been found to be paramount to

Trust in the midwives was paramount to women choosing a homebirth. Women and their partners felt safe and supported in the knowledge that their midwives displayed adequate knowledge, training and carried emergency equipment. Transfer systems were also reassuring to women and their partners, who had to discuss these aspects of emergency 
care during the process of choosing their birthplace. Trust in caregivers has been found to be important in other studies [26,51], and women having homebirths describe a close relationship with their midwives [52]. Similarly, the confidence women have in the birth process itself, and their ability to have a natural, normal birth was a strong theme in this study. This trust and belief in a normal birth process is common in other studies of women having homebirths $[26,19,20]$.

The limitations of this study are its size, its multiparous sample, and the specificity to a publicly-funded model of care within an area of Sydney, Australia. The sample were all English-speaking women living in the St George area, and not wholly representative of the area. Findings may be quite different in a primiparous sample. It is possible that the researcher's personal views on homebirth may have influenced the data analysis however this is a recognised limitation of all qualitative research that uses thematic analysis. Despite these limitations, the study is the first to explore the experiences of women having a publiclyfunded homebirth and there are likely to be messages and resonances for researchers, midwives, managers and policy makers who are considering or developing such models in Australia.

\section{CONCLUSION}

The women in this study were confident in their ability to give birth at home, boosted by the availability of hospital care, if needed. Their confidence often grew through antenatal preparation, and by seeking like-minded people. They described the importance of their midwives to build confidence. Often there was a protective selectivity on who they told about their plans for a homebirth. Both women and their families were very reassured that should complications arise, there were seamless back-up systems of hospital transfer in place. More research on women's choice of birth place in Australia would be valuable. 


\section{REFERENCES}

1. Laws, P.J. and L. Hilder, Australia's Mothers and babies 2006. 2008, Perinatal statistics series no. 22. Cat. no. PER 46.: Sydney: AlHW National Perinatal Statistics Unit.

2. MacDorman, M., F. Menacker, and E. Declercq, Trends and Characteristics of Home and Other Out-of-Hospital Births in the United States, 1990-2006 in National vital statistics reports; vol 58 no 11. 2010, National Center for Health Statistics: Hyattsville, MD.

3. Office for National Statistics, Birth Statistics: Review of the National Statistician on births and patternsof family building in England and Wales, 2008. 2009, Office for National Statistics London.

4. BirthChoiceUK. Home Birth 2009. Available at: http://www.birthchoiceuk.com/Professionals/index.html. Accessed March 12, 2010

5. Euro-Peristat project, European Perinatal Health Report. 2008, Perinatal Registry: Utrecht, Netherlands.

6. Australian Medical Association. AMA Submission to the Maternity Services Review. 2008 Available at:

www.ama.com.au/.../Maternity_Services_Review_Submission.pdf. Accessed May 28, 2010.

7. Royal Australian \& New Zealand College of Obstetricians \& Gynaecologists, College Statement: Homebirths. 2008, RANZCOG.

8. Commonwealth of Australia. Midwife Professional Indemnity (Commonwealth Contribution) Scheme Bill 2009. 2009; Available at:

http://parlinfo.aph.gov.au/parllnfo/search/display/display.w3p;query=ld:\%22legislation \%2Fbillhome\%2Fr4153\%22. Accessed June 12, 2010.

9. Homer C, Caplice S. Evaluation of the publicly-funded homebirth program in South East Sydney Illawarra Area Health Service. 2007, Centre for Midwifery, Child and 
Family Health, Faculty of Nursing, Midwifery and Health, University of Technology Sydney: Sydney.

10. Nixon A, Bryne J, Church A. An Evaluation of the Northern Women's Community Midwifery Program. 2003, Department of Human Services: Adelaide.

11. Homer CSE, Nicholl M. Review of homebirths in Western Australia. 2008, Department of Health WA: Perth.

12. Elder (Aug 92009 'hospitals deliver help to home-births push. The age.com.au URL http://www.theage.com.au/national/hospitals-deliver-help-to-homebirths-push20090808-edm4.html

13. Benson K. Homebirth mothers being refused prescriptions, in Sydney Morning Herald. 2010, Fairfax Media: Sydney.

14. Dahlen H, Barclay L, Homer CSE. Peparing for the First Birth: Mothers' Experiences at Home and in Hospital in Australia. Journal of Perinatal Education, 2008. 17(4): p. 22-32.

15. AskOxford.com. Compact English Oxford Dictionary. 2010. Available at:

http://www.askoxford.com:80/concise oed/confidence?view=uk. Accessed June 16, 2010.

16. Ip W-Y, Tang CSK, Gogins WB. An educational intervention to improve women's abiliity to cope with childbirth. J Clin Nurs, 2009; 18:2125-2135.

17. Christiaens W. Bracke P. Assessment of social psychological determinanats of satisfaction with childbirth in a cross-national perspective. BMC Pregnancy and Childbirth. 2007; 7(26).

18. Lowe NK. Self-efficacy for labor and childbirth fears in nulliparous pregnant women. $J$ Psychosom Obstet Gyn, 2000; 21:219-224

19. Viisainen K. Negotiating control and meaning: home birth as a self-constructed choice in Finland. Soc Sci Med, 2001; 52(7):1109-21. 
20. Boucher D. Bennett C, McFarlin B, Freeze R. Staying Home to Give Birth: Why Women in the United States Choose Home Birth. J Midwifery Wom Heal, 2009; 54(2):119-126.

21. Johnson KC, Daviss B.Outcomes of planned home births with certified professional midwives: large prospective study in North America. BMJ. 2005; 330(7505):1416-9.

22. Olsen O, Jewell MD. Home versus hospital birth. Cochrane DB Syst Rev.1998; Issue 3. Art No.: CD000352

23. de Jonge A, van der Goes BY, Ravelli ACJ, Amelink-Verbourg MP, Mol BW, Nijhuis JG, Bennebroek Gravenhorst J, Buitendijk SE. Perinatal mortality and morbidity in a nationwide cohort of 529688 low-risk planned home and hospital births. BJOG: Int J Obstet Gy, 2009; 116(9);117-1184

24. Janssen PA, Saxell L, Page L, Klein MC, Liston RM, Shoo KL. Outcomes of planned home birth with registered midwife versus planned hospital birth with midwife or physician. CMAJ. 2009; 181(6-7);377-383

25. Dahlen H. Undone by fear? Deluded by trust? Midwifery. 2009; 26(2);147-8

26. Lindgren H, Hildingsson I, Radestad I. A Swedish interview study: parents' assessment of risks in home births. Midwifery, 2006; 22(1):15-22.

27. Janssen PA. Henderson AD. Vedam S. The Experience of Planned Home Birth: Views of the First 500 Women. Birth, 2009; 36(4):297-304

28. Downe S, Davis-Floyd RE. Normal childbirth: evidence and debate. 2004, London: Elsevier Health Sciences.

29. Davis-Floyd RE, Mather FS. The technocratic, humanistic and holistic paradigms of childbirth. MIDIRS. 2002; 4(12):500-506.

30. Cheyney M, Everson C. Narratives of risk: speaking across the Hospital/Homebirth divide. Anthropology News. 2009; 50(3):7-8

31. Devine M. A home birth is not a safe birth. 2009. Available at: http://www.smh.com.au/lifestyle/lifematters/a-home-birth-is-not-a-safe-birth20090408-aOs3.html. Accessed April 15, 2010 
32. Bick D. Media portrayal of birth and the consequences of misinformation. Midwifery. $2010 ; 26: 147-148$.

33. McMurtrie J. Catling-Paull C, Teate A, Caplice S, Homer CSE, Chapman M. St. George Hospital Homebirth: outcomes of the first 100 women. ANZCOG, 2009; 49(6): 631-636.

34. NSW Health, Midwives - NSW Health - Credentialling Framework, Nursing and Midwifery Office, Editor. 2005: Sydney.

35. Gibson WJ. Brown A. Working with Qualitative Data. 2009, London: Sage Publications Ltd.

36. QSR International. NVivo qualitative data analysis software. 2006.

37. Morison S. Hauck Y, Percival P, McMurray A. Constructing a home birth environment through assuming control. Midwifery, 1998; 14(4):233-241.

38. Lindgren HE, Radestad IJ, Christensson K, Wally-Bystrom K, Hildingsson LM. Perceptions of risk and risk management among 735 women who opted for a home birth. Midwifery, 2010; 26:163-172.

39. Jackson P. Calmbirth. 2007. Available at: http://www.calmbirth.com.au/index.html. Accessed April 16, 2010

40. Crowe K. von Baeyer C. Predictors of a positive childbirth experience. Birth, 1989; 16(2): 59-63.

41. Rouhe H. Salmela-Aro K, Halmesmaki E, Saisto T. Fear of childbirth according to parity, gestational age, and obstetric history. BJOG: Int J Obstet Gy, 2009; 116(1):6773.

42. Laursen M, Johansen C, Hedegaard M. Fear of childbirth and risk for birth complications in nulliparous women in the Danish National Birth Cohort. BJOG: Int J Obstet Gy. 2009; 116(10):1350-5.

43. Williams DJ, Noyes JM. How does our perception of risk influence decision-making? Implications for the design of risk information. Theoretical Issues in Ergonomics Science. 2007; 8(1):1-35. 
44. Neuhaus W, Piroth C, Klencke P, Gohring UJ. Mallman P. A psychosocial analysis of women planning birth outside hospital. J Obstet Gynaecol. 2002; 22(2):143-9.

45. Dahlen H, Barclay L, Homer CSE. The novice birthing: theorising first-time mothers' experiences of birth at home and in hospital in Australia. Midwifery. 2010; 26(1):5363.

46. Pilley Edwards N, Murphy-Lawless J. The Instability of Risk: Women's Perspectives on Risk and Safety in Birth, in Risk and Choice in Maternity Care: an international perspective, Symon A. Ed. 2006; Churchill Livingstone: London.

47. Fordham S, Women's views of the place of confinement. Brit J Gen Pract. 1997; 47(415):77-80.

48. Bailes AJ. Jackson ME. Shared responsibility in home birth practice: collaborating with clients. J Midwifery Wom Heal. 2000; 45(6):537-543.

49. Newburn M. Culture, control and the birth environment. Practising Midwife. 2003; 6(8):20-5.

50. Page L. Choice, control and continuity: the three 'Cs'. Modern Midwife. 1992; 2(4):810.

51. Bluff R. Holloway I. 'They know best': women's perceptions of midwifery care during labour and childbirth. Midwifery. 1994; 10(3):157-64.

52. Borquez HA. WiegersTA. A comparison of labour and birth experiences of women delivering in a birthing centre and at home in the Netherlands. Midwifery. 2006; 22(4): 339-47. 